\title{
Narrative Representation and Phenomenological Knowledge
}

Rafe McGregor

\begin{abstract}
The purpose of this paper is to demonstrate that narrative representations can provide knowledge in virtue of their narrativity, regardless of their truth value. I set out the question in section 1, distinguishing narrative cognitivism from aesthetic cognitivism and narrative representations from non-narrative representations. Sections 2-3 argue that exemplary narratives can provide lucid phenomenological knowledge, which appears to meet both the epistemic and narrativity criteria for the narrative cognitivist thesis. In section 4 I turn to non-narrative representation, focusing on lyric poetry as presenting a disjunctive objection: either lucid phenomenological knowledge can be reduced to identification and fails to meet the epistemic criterion or lucid phenomenological knowledge is provided in virtue of aesthetic properties and fails to meet the narrativity criterion. I address both of these problems in sections 5-6 and close with a tentative suggestion as to how my argument for narrative cognitivism could be employed as an argument for aesthetic cognitivism.
\end{abstract}

Keywords: Aesthetic cognitivism, Narrative representation, Phenomenological knowledge

\section{Narrative Representation}

More than thirty years ago Catherine Wilson [1983: 489] described the question of cognitive value as one of the most passionate debates within the philosophy of art. In his 2008 survey article, John Gibson [2008: 586-87] suggests that the dispute has intensified and situates it in the context of the more fundamental inquiry into the relation between humanistic and aesthetic values of art. Katherine Thomson-Jones [2005: 376] provides a neat summary of 
the issue as currently contested: 'Aesthetic cognitivism and aesthetic anti-cognitivism can be defined as opposing responses to two questions: (1) Can art provide knowledge? And, if it can, (2) how is this aesthetically relevant?' The aesthetic cognitivist answers the first question in the affirmative, meeting the epistemic criterion (1). In order to meet the aesthetic criterion (2) a necessary relation between the capacity of a work to provide knowledge and the success (or lack thereof) of that work qua art must be established. ${ }^{1}$ The thesis of aesthetic cognitivism can thus be defined as follows:

(AC) Works of art can provide knowledge in a manner that is aesthetically relevant. Anti-cognitivists dispute either the epistemic or the aesthetic criterion. I want to approach the cognitivist debate in terms of narrative rather than aesthetic representation and this paper is therefore an inquiry into narrative cognitivism, defined as:

(NC) Narrative representations can provide knowledge in virtue of their narrativity. The two criteria for NC are: (1) that the narrative representation provides knowledge (epistemic criterion) and (2) that the narrative representation provides knowledge in virtue of its narrativity (narrativity criterion).

My starting point is to take 'narrative' and 'story' as synonymous. Representations of real and fictional sequences of events can be communicated in narrative and non-narrative form by a variety of means, including the written and spoken word and still and moving images. I shall distinguish between narrative and non-narrative representations, but not between narratives that represent real and fictional events or between linguistic and visual narratives. A minimal narrative is the product of an agent that represents:

\footnotetext{
${ }^{1}$ For the purposes of this paper, I shall follow Thomson-Jones in assuming that there is a strong relation between aesthetic value and value qua art, i.e. that aesthetic value is at the very least a significant component of value qua art.
} 
(a) one or more agents ${ }^{2}$ and

(b) two or more events which are

(c) connected.

Gregory Currie [2010: 2] begins his discussion of narrativity by noting that all representations are created rather than found and therefore the product of a process of intentional shaping. Narrativity is gradational rather than categorical, i.e. admits of degrees. The manner in which (a) and (b) contribute to narrativity is straightforward, but (c) has been subject to much debate. Peter Lamarque [2014: 52] takes the broadest view of the requisite connection, claiming that:

there must be some more or less loose, albeit non-logical, relation between the events. Crucially, there is a temporal dimension in narrative, not just in the sense that component sentences are tensed but also in that there must be a temporal relation between the events, even if just that of simultaneity.

I shall accept this loose temporal connection for minimal narratives, the consequence of which is that the following utterance meets the criteria for a minimal narrative: 'Katy kicked the stone and missed her bus.' As such, Currie [2010: 34] is correct to claim that it is not the concept 'narrative' that is philosophically interesting, but 'the concept thing high in narrativity.'

In contrast to a minimal narrative, an exemplary narrative $e^{3}$ is the product of an agent that is high in narrativity in virtue of representing:

(i) one or more agents and

(ii) two or more events which are

\footnotetext{
${ }^{2}$ Peter Goldie [2012: $19 \mathrm{fn} .20$ ] notes the possibility of narratives with no human characters, but excludes these from his discussion. I shall not stipulate that the agents must be human, merely that they are capable of intentional action, such as the anthropomorphised rabbits in Richard Adams' Watership Down and the false Maria robot in Fritz Lang's Metropolis.

${ }^{3}$ The term is from Currie [2010: 35].
} 
(iii) causally connected,

(iv) thematically unified, and

(v) conclude.

Regarding (iii), Noël Carroll [2001: 126] proposes the following connection: 'the earlier events in the sequence are at least causally necessary conditions for the causation of later events and/or states of affairs (or are contributions thereto).' I shall accept that non-minimal narratives have a causal connection between events and that exemplary narratives have a causal connection which is so strong as to contribute to the thematic unity of the narrative. Currie [2010: 39] defines thematic unity as follows:

unity is provided by a focus on some common thread in the activity of particular persons in particular connected circumstances, though narratives often do have, in addition, general thematic unity in that we are invited to generalize from the case in question.

Carroll [2013: 123] divides narratives into two broad categories: episodic narratives, consisting of smaller stories where causal linkage is weak and frequently achieved by means of a recurring protagonist; and unified narratives, where causal linkage is strong and there is a smooth transition from beginning to middle to end. The significance I have accorded to thematic unity restricts exemplary narratives to the latter category.

In his taxonomy of historical representations, Hayden White [1980: 21-23] identifies the absence of closure as characterising a text as a chronicle rather than a narrative: a chronicle merely terminates in medias res, leaving the reader to impose his or her own meaning upon the sequence of events represented. Carroll [2013: 123] describes the phenomenon as 'the almost palpable sensation that the story has finished-up at exactly the right spot.' In the taxonomy I am establishing, chronicles meet the criteria for minimal narratives, but not 
exemplary narratives. White's insistence on the importance of closure might be considered overly-demanding and Carroll [2012: 355-56] claims that soap operas and national histories are examples of narrative representations without closure. Soap operas are indeed high in narrativity, but they lack thematic unity and are episodic in nature. Every soap opera has several stories running parallel, usually involving characters who live in the same place, and the narrativity within these sub-narratives may be high despite the absence of an overarching, thematic connection. National histories are similar in that they take a place as their primary focus, involve a large number of characters and sub-narratives, and are typically lacking in an overarching theme. On the basis that they are at best borderline cases, I shall exclude both soap operas and national histories from the category of exemplary narratives.

Given (iii) to (v) above, exemplary narratives can be distinguished from lists, annals, chronicles, and diaries. Examples include: the Bayeux Tapestry, William H. Prescott's History of the Conquest of Peru, Wharton's Age of Innocence, Leni Riefenstahl's Triumph of the Will, Orson Welles' Citizen Kane, and Art Spiegelman's Maus. It could be argued that the three features in virtue of which a representation is high in narrativity are aesthetic properties or that narrativity itself is an aesthetic property. There is a strong case that the imposition of narrative form upon a sequence of events, the author's decision to represent those events as a story, constitutes the author's intention to shape the representation in an aesthetic manner. Indeed, it is difficult to describe the features of exemplary narratives without employing aesthetic terms and it is no coincidence that so many exemplary narratives are regarded as works of art. For reasons I explain in section 6, I shall nonetheless proceed as if narrative properties are not a sub-category of aesthetic properties, presenting an argument for $\mathrm{NC}$ that is restricted to exemplary narratives. 


\section{Knowledge \& Narrativity}

Dorothy Walsh [1969: 96] employs Gilbert Ryle's The Concept of Mind to delineate two distinct types of knowledge:

A philosophical analysis of the meaning of "know" that is at present widely influential is one that finds two fundamental and irreducible meanings in use. There is knowing in the sense of knowing that (such and such is so) and there is knowing in the sense of knowing how (to perform some act).

She [1969: 103] then differentiates between experience as awareness of and experience as living through and advances the latter as a third type of knowledge:

Recognizing that such and such is so with reference to some kind of human experience is not the same as realizing what this might be like as a lived experience. Confession of failure to understand, in the sense of realize, is perfectly compatible with absence of doubt concerning matter-of-fact.

Wilson [1983: 492] refers to this realisation as 'knowing what', short for 'knowing-what-itis-like', and Gibson [2008: 582] as 'experiential knowledge'. Walsh [1969: 105] claims that unlike actual experiences, the virtual experiences of literary works can be experienced by anyone who engages with the work such that they are shareable and can provide knowledge. Alex Burri [2007: 310] holds a similar view, maintaining that the practice of art aims at the subjective rather than objective representation of reality, 'to conduct some kind of phenomenological investigation into how things appear to us.' I shall employ the term phenomenological knowledge:

(PK) The realisation of what a particular lived experience is like. 
In section 1 I identified the difference between minimal narratives and exemplary narratives as causal relations, thematic unity, and closure. These three features combine to create a perspective that is absent in minimal narratives. Exemplary narratives are essentially perspectival, as Peter Goldie [2012: 2] makes clear in his definition:

a representation of those events which is shaped, organized, and coloured, presenting those events, and the people involved in them, from a certain perspective or perspectives, and thereby giving narrative structure - coherence, meaningfulness, and evaluative and emotional import - to what is related.

Lamarque [2014: 9] refers to this perspectival nature as opacity:

narratives are "opaque" somewhat as paintings are opaque. ${ }^{4}$ They have the same kind of intentionality, not just as products of intentions, but also, in different ways and to different degrees, through expressing thoughts or a point of view on what they represent. This seems to be true of all narratives, not just those of literary fiction. The perspective that constitutes an exemplary narrative produces a framework, which Currie [2010: 86] identifies as 'a preferred set of cognitive, evaluative, and emotional responses to the story.' He notes that there are no set of explicit instructions, but that the framework is expressed in the representation of the sequence of events. From this framework Currie [2010: 106] proceeds to

the standard mode of engagement with narrative. Narratives, because they serve as expressive of the points of view of their narrators, create in our minds the image of a persona with that point of view, thereby prompting us to imitate salient aspects of it notably evaluative attitudes and emotional responses. In taking on those responses, we thereby come to adopt, wholly or in part, the framework canonical for that work.

\footnotetext{
${ }^{4}$ The opacity of paintings is that, unlike photographs, 'they do not represent simply in virtue of standing in a causal relation to their subjects' [Lamarque 2014: 9].
} 
The standard mode of engagement (SME) is thus the adoption, by audiences, of the framework that the author invites one to adopt. ${ }^{5}$

It is this framework - the preferred set of cognitive, evaluative, and emotional responses that has the capacity to provide PK. Authors can provide different frameworks for the same characters and events. In Triumph of the Will, e.g., Leni Riefenstahl frames Hitler as a messianic saviour who descends from the heavens to lead the German people to glory. ${ }^{6}$ In contrast, Oliver Hirschbiegel frames Hitler as an evil megalomaniac who sacrifices millions of people - including the German nation - for his self-aggrandisement in Downfall. In the former, the audience comes to realise why many Germans supported Hitler; in the latter, the audience comes to realise the full extent of his malevolence in his determination to destroy Germany as well as himself. Gibson [2008: 582-83] shows how art provides PK, using two works that are both exemplary narratives as examples:

Drawing solely on my own experiences and my preferred books of theory, I will acquire no significant knowledge of what it is like to be a victim of systematic racial oppression or an immigrant struggling to make his way to an unwelcoming country. But I can read Ralph Ellison's Invisible Man or watch Elia Kazan's America, America and in so doing acquaint myself with a region of human experience that would otherwise remain unknown to me.

In order to acquire PK, it is necessary not just to experience the respective representations, but to adopt the SME to each. If, e.g., one fails to adopt the SME to Invisible Man - the

\footnotetext{
${ }^{5}$ For the purposes of this paper, I shall use 'author' to describe the producer of a narrative regardless of the representational medium employed. Some narrative representations feature a narrator who is distinct from the author, but I shall not discuss the complexities of this distinction (see: Currie [2010: 65-69]). I shall also use 'audience' to describe the people who engage with a narrative representation regardless of the medium in which that representation is experienced.

${ }^{6}$ Riefenstahl denied the framework I have described here post-war, which is hardly surprising. For an unsurpassed philosophical discussion of the film, see: Devereaux, Mary 2001. Beauty and evil: the case of Leni Riefenstahl's Triumph of the Will, in Aesthetics and ethics: Essays at the intersection, ed. J. Levinson, New York: Cambridge University Press: 227-256.
} 
anonymous narrator as sympathetic - then one will not realise what it is like to be a victim of systematic racial oppression. In an extreme case such as Triumph of the Will, the many contemporary viewers who refuse to adopt Riefenstahl's framework will not realise what it is like to see Hitler as heroic. The documentary can provide such viewers with other types of knowledge, e.g. knowledge that Hitler was regarded as a saviour by many Germans, but not the PK identified. Viewers who do adopt Riefenstahl's framework do not have to become temporary or permanent National Socialists, but they must temporarily set aside their contempt for Hitler if they are to gain the PK. The same would be true of a Ku Klux Klan member reading Invisible Man.

The knowledge with which I am concerned is a sub-category of PK that is provided by exemplary narratives, lucid phenomenological knowledge:

(LPK) The realisation of what a particular lived experience is like by means of the reproduction of a particular experience of a particular character for the audience who adopt the standard mode of engagement to the narrative representation.

Tzachi Zamir demonstrates that Shakespeare provides LPK in reproducing a particular experience of a particular character for the audience not by means of empathy but by structuring the representation so that the experience is acted by the actors and re-enacted by the audience. One of the examples Zamir [2007: 113-125] employs is Romeo and Juliet, where Romeo's experience of forgetting about Rosaline - with whom he is deeply in love when the play opens - is reproduced in the experience of the audience. Romeo forgets about his lover and the audience forgets about the lover of the protagonist of the play: the play therefore provides LPK of what it is like to forget someone who is important. Zamir [2007: 147] maintains that Shakespearean drama conveys rather than describes this knowledge: 
'Conveying is a mode of telling that involves configuring in highly specific ways the state of mind of recipients. It reenacts an experiential structure that overlaps and resembles the experience that it describes (though is not identical to it).'

The state of mind of the audience who adopt the SME is configured by the framework, which - in the case of Romeo and Juliet - reproduces an experience of Romeo's in the audience, the forgetting of Rosaline. The experience may be reproduced for the audience that adopts the framework in part as well as wholly, but must be produced by the framework if it is to provide LPK. The experience is reproduced rather than replicated because the audience does not forget about their own loved ones, like Romeo, but about his lover. The audience's experiences nonetheless overlap and resemble Romeo's because they both involve forgetting someone that is important (one's own lover for the character and the lover of the protagonist for the audience). Zamir's other examples - which concern the ambivalence of mature love in Antony and Cleopatra and the limitations of language in Hamlet - are not as convincing. He [2007: 149] is, however, seeking to delineate a fourth type of knowledge altogether, 'knowing the shapes through which things may come', which may be why he applies conveying more loosely than I do LPK. I suspect that the provision of LPK is not only rare, but extremely rare, a point to which I shall return in section 5.

Another example of LPK occurs in my paper 'Cinematic Philosophy: Experiential Affirmation in Memento'. Here, I [2014: 58-60] argued that the SME with Christopher Nolan's Memento provides the audience with the knowledge that memory is essential to understanding and thus for a version of AC. The means by which the knowledge I described is provided is Nolan's employment of narrative structure. The protagonist, Leonard, has a severe case of anterograde amnesia, and the extraordinary complexity of the narrative places 
the audience in a similar epistemic situation because of the extreme difficulty in following the sequence of events as represented. ${ }^{7}$ To take just one instance, the colour scenes in the film are shown in reverse order such that the audience, like Leonard, does not know the sequence of events that has just occurred, but, unlike Leonard, knows part of the sequence of events that will occur. Memento thus provides LPK of what it is like to have anterograde amnesia in virtue of its narrativity. The framework of the film creates an experiential structure for the audience that overlaps and resembles Leonard's because neither he nor the audience are aware of his most recent actions. ${ }^{8}$ The LPK in Memento and Romeo and Juliet is a distinct version of the PK provided by Triumph of the Will, Downfall, Invisible Man and America, America. In all six cases, the narrative representation provides knowledge of what a lived experience is like (PK), but only in the first two is that knowledge gained by means of the reproduction of an experience of a character in the experience of the audience (LPK). In the remainder of this paper I shall argue that LPK meets both the epistemic criterion and the narrativity criterion and thus for NC.

\section{Epistemic Criterion: Evidence}

In her discussion of Walsh, Wilson [1983: 493-94] examines D.Z. Phillips' interpretation of Age of Innocence and maintains that there is 'a wide logical gap between the realization of what it would be like to have Newland Archer's experiences and the realization that a certain popular conception of reasonable action is, in a certain sense, fraudulent.' Phillips claims that the novel has provided him with knowledge of the artificiality of an abstract concept of reasonableness, but Wilson argues that this knowledge is not entailed by Walsh's knowledge

\footnotetext{
${ }^{7}$ For a comprehensive examination of this structure, see: Kania, Andrew 2009. Scene Tables, in Memento (Philosophers on Film), ed. A. Kania, Abingdon: Routledge: 13-22.

${ }^{8}$ Both of the paradigmatic instances of LPK I have described exploit limitations in the memories of the audience. I am tempted to explore the potential connection between the similar temporal dimensions of theatre and cinema with LPK, but I expect that most people who read Romeo and Juliet also forget about Rosaline.
} 
of what it is like to be the protagonist. The logical gap points to a 'serious ambiguity in Walsh's formulation' because there are two senses of PK, shallow and deep [Wilson 1983: 494]. Wilson's [1983: 494-95] view is that in order to meet the epistemic criterion for AC, a literary work must revise or modify the concepts of readers. George Orwell's Down and Out in Paris and London, e.g., thus has the potential to provide knowledge in at least the following two ways:

(1) What it is like to be poor and lonely in the big city.

(2) Re-conceptualisations of poverty, loneliness, or anonymity.

Wilson's claim is that (1) does not meet the epistemic criterion, but (2) does.

I think that (2) is problematic as an epistemic criterion for AC, but my interest is in Wilson's claim that (1) is a shallow sense of PK. Walsh's argument for the knowledge provided by literary works is restricted to the type of knowledge in (1) - i.e., PK - and she maintains that PK is knowledge despite the fact that (1) has no truth value. Gibson [2008: 582] offers further support for (1) as a type of knowledge:

For all sorts of anatomical, temporal and financial reasons, reality will never offer us the occasion to experience the world as Madame Bovary, Achilles or King Midas did. Art can be seen compensating for the extremely limited way we each encounter the world by offering us an occasion to do in the imagination what real life can never make possible. Surely the occasion to witness this great variety of kinds of human experience is a potential source of cognitive insight.

Wilson's criticism that (1) does not meet the epistemic criterion is thus open to dispute, but she has a related concern, which is more convincing: Walsh not only states that PK is not truth-conditional, but that it is inappropriate to demand proof of PK [Wilson 1983: 492]. As Walsh admits, the acquisition of knowledge that and knowledge how are readily proved - by 
statement and performance respectively. To make Wilson's point in another way: even if one accepts that PK meets the epistemic criterion, there is no criterion for PK itself, i.e. how does one know that one has gained PK? Or, how can I offer evidence for my claims (in section 2) that Invisible Man provides knowledge of what it is like to suffer racial prejudice and Triumph of the Will knowledge of what it is like to admire Hitler? Walsh's claim that proof is inappropriate to PK will fail to convince many philosophers and cast doubt on whether PK is a third type of knowledge.

In contrast to PK, LPK is verifiable. If I am asked to prove that Invisible Man provides PK of suffering racial prejudice I may quote critical interpretations of the novel, but my ultimate response is going to be to direct the inquirer to the novel, i.e. to claim that if a reader adopts the SME, the reader will acquire the PK in question. But if the reader disputes this, then we will have reached an impasse. If I am asked to prove that Memento provides LPK of anterograde amnesia, I shall once again direct the inquirer to the film, but the difference is that a clear criterion has been established: if the viewer is not confused by the narrative structure, then he or she has not gained the LPK; if the viewer is confused by the narrative structure, then he or she has gained the LPK. ${ }^{9}$ My interest in LPK is in paradigmatic cases, in cases where the critical impasse mentioned is implausible. The viewer who keeps Rosaline in the forefront of her mind throughout Romeo's exchanges with Juliet does not adopt the SME to Romeo and Juliet any more than the viewer who uses the pause function on his DVD to make notes on Memento.

\footnotetext{
${ }^{9}$ For readers of this paper who have not experienced Memento, I should note that the narrative complexity is such that Nolan himself claimed he was unable to predict the sequence in which the scenes appeared, after over a thousand viewings. See: Gaut, Berys 2011. Telling Stories: Narration, Emotion, and Insight in Memento, in Narrative, Emotion, and Insight, eds N. Carroll and J. Gibson, University Park, PA: Pennsylvania State University Press: 23-44.
} 
Recall that the model for an LPK claim is that the representation reproduces a particular experiential structure that it represents in respect of a particular character in the narrative for the audience. The criterion for LPK will thus vary in each instance, but is nonetheless verifiable in a way in which PK claims are not:

(i) Romeo and Juliet provides LPK by reproducing Romeo's forgetting of Rosaline in the audience.

The criterion for LPK in Romeo and Juliet is that the audience forgets about Rosaline.

(ii) Memento provides LPK by reproducing Leonard's experience of anterograde amnesia in the audience.

The criterion for LPK in Memento is that the audience is unable to understand the sequence of events represented.

The criteria in both (i) and (ii) can be verified by empirical studies of audiences as well as theoretical studies of the SME for each work. In paradigmatic cases of LPK both the SME and the knowledge provided by the SME are readily apparent. As such, LPK is not subject to the no-evidence objection to PK.

\section{Non-Narrative Representation}

My argument for NC is reliant upon narrative representations providing LPK in virtue of their narrativity. In section $3 \mathrm{I}$ argued that LPK meets the epistemic criterion for NC. In order to meet the narrativity criterion for NC, LPK must be provided in virtue of the narrativity of the representation and in section 2 I argued that LPK is provided by means of the SME, which is itself determined by the narrative framework. An objection to NC on the basis of the narrativity criterion would have to show that LPK is not provided in virtue of the narrativity 
in the representation, but in virtue of something else. It is important to note that I am not arguing for the following, stronger, claim about narrative representations:

(NC*) Exemplary narratives can provide unique knowledge in virtue of their narrativity.

In order for $\mathrm{NC}^{*}$ to hold, LPK would not only have to be provided by representations in virtue of their narrativity, but would have to be exclusive to narrative representations. NC is, however, compatible with non-narrative representations - such as lyric poems - providing LPK in virtue of a feature other than narrativity. The case of lyric poetry is worth considering because although it does not constitute a direct objection to $\mathrm{NC}$, it exposes a disjunction that is problematic.

Anna Christina Ribeiro [2009: 68] provides a useful taxonomy of poetry in 'Toward a Philosophy of Poetry', dividing poems into three sub-categories: lyric, dramatic, and epic. Epic poems are distinguished by having a narrator, dramatic poems by characters having their own voices, and both are typically narrative representations. Lyric poems, which are 'the prevalent mode of poetic expression', are characteristically - but neither necessarily nor exclusively - non-narrative representations written in verse and in the first person [Ribeiro 2009: 68]. Gibson [2011] agrees that 'much lyric poetry is not fictional or even narrativebased: much lyric poetry tells no story, properly so-called.' I shall take it as uncontroversial that lyric poetry, which paradigmatically consists of versified, first-person accounts of personal experiences, is a non-narrative mode of representation. As such, if lyric poems provide LPK, it cannot be in virtue of their narrativity.

In section 2 I defined LPK in terms of the SME, which is the audience's adoption of the author's framework. The framework was described as a product of the perspective of an 
exemplary narrative, and the perspective as composed of causal relations, thematic unity, and closure. If one replaces 'narrator' with 'poet' in Currie's definition of SME, however, the SME might equally apply to poems and Lamarque [2009: 50] claims that the content of poetry - lyric poems written in the first-person in particular - is 'filtered through a particular point of view', i.e. essentially framed by the poet. Both narratives and poems are, in Lamarque's terms, opaque, and employ a framework that invites a SME. One might resist collapsing the SME for narrative and poetic representations by emphasising the difference between the ways in which the respective frameworks are created. If one accepts that most poems are lyric poems and most prose (at least minimal) narratives, then Nigel Fabb's [2009: 55-56] characterisation of poetry as being rich in both formal features and figurative language is promising. Ribeiro [2009: 66] reiterates these two characteristics as typically distinctive of poetry, but they are neither necessary nor exclusive so the question of whether poetic frameworks differ from narrative frameworks in any significant way appears to resist an unequivocal answer.

This ambiguity produces the following disjunction: either

(1) narrative and poetic frameworks are too similar to admit of significant distinction, or

(2) although narrative and poetic frameworks appear similar, the distinction between their different modes of representation is significant.

Both (1) and (2) provide grounds for objections to NC. If (1) is true, then the means by which lyric poems typically invite the SME - identification with the poet - suggests that the LPK provided by narrative representations can be reduced to identification with a particular character. If LPK was provided in virtue of identification, then it would (as I explain in section 5) fail to meet the epistemic criterion for NC. If (2) is true, then the combination of 
works of poetry and prose in the category of literature suggests that when LPK is provided by narrative representations it is in virtue of their aesthetic rather than narrative properties. Indeed, the philosophers I have been examining here - Gibson, Walsh, Wilson, Zamir - have all been concerned with the relationship between knowledge and art, literature, or drama, i.e. with AC. If LPK was provided in virtue of aesthetic properties, then it could (as I show in section 6) fail to meet the narrativity criterion for NC.

\section{Epistemic Criterion: Identification}

If narrative frameworks and poetic frameworks are too similar to admit of significant distinction, then my argument for LPK in narrative representations may have erred in its focus on the importance of the narrative features of the framework through which LPK is provided. If lyric poems are typically personal experiences written or voiced in the first person, then one could replace 'a particular character' with 'the poet' in my definition of LPK and argue that LPK was provided by lyric poems in virtue of non-narrative features.

Ribeiro's [2009: 69-70] discussion of the typical audience engagement with poetic representations reveals precisely this possibility and is worth quoting in full:

When listening to or reading a poem, we begin by hearing someone else's voice, by attending to what the poetic persona might have to share with us. Without presuming to account for all poetry reading experiences, I submit that, typically, by the end of the poem we have come to identify with that voice. I do not mean by this that we suddenly come to think that we are the poet, or that we are the writers of the poem. I mean an identification in the sense that we feel that we could have written those words (if only we had the talent to express ourselves as well), because they express something that we, too, feel or have felt, think or have thought, and sometimes even 
thoughts and feelings we never realized we had but that now, seeing them expressed, we find resonating with something within ourselves. Our experience of lyric poems is therefore peculiarly personal: we either assume the role of the speaker in the poem, or of the one who is spoken to. This makes the reading of poems very immediate and subjective; we are not being told a story, objectively, of what happened to whom and how they felt, but instead a very personal account of how one felt, in a way that invites us to recognize similar feelings or experiences or thoughts in ourselves.

Ribeiro's description matches LPK closely and suggests that many - if not most - poems provide LPK in virtue of the process of identification she describes. In the SME with a particular poem one comes to recognise the poet's thoughts, feelings, or experiences as one's own. In reading, e.g., T.S. Eliot's 'Gerontion' therefore, I identify with the sadness, regret, resignation, and disgust Eliot expresses, appropriating these feelings as my own. The SME with Romeo and Juliet causes me to forget about Rosaline and thus reproduces Romeo's experience in me, but the SME with 'Gerontion' seems to be paradigmatic LPK because it is not just one experience of one character (Romeo's forgetting), but a multitude of the poet's thoughts and feelings that are reproduced. There is thus a sense in which the whole poetic experience is an experience of the acquisition of LPK where the whole narrative experience of Romeo and Juliet is not. The problem for my argument for NC is that poems are widely considered to be more resistant to interpretation and paraphrase than narrative representations. In section 3 I distinguished LPK from PK by stating that the former kind of knowledge was specifiable and could therefore meet the demand for evidence. But many poems demonstrate a kind of ineffability that seems to preclude the paraphrasability with which I characterised LPK. On this objection, my conception of LPK is flawed because its 
paradigmatic occurrence is in lyric poems, which will typically fail to meet the epistemic criterion for $\mathrm{NC}$ (as discussed in section 3).

For the purposes of my response, I shall accept that there is no significant distinction between poetic and narrative frameworks and that the SME with poetic representations typically involves the audience's identification with the poet, as described by Ribeiro. The reason that $\mathrm{NC}$ is not subject to the no-evidence objection is that the process by which LPK is provided in narrative representations is distinct from identification. The representation (by means of the narrative framework) reproduces (without of course replicating) the structure of experience in a manner that involves a feature which is similar to anagnorisis, the moment of recognition Aristotle [X: 1452a13-23] identified as an element of narrativity. Recognition is, for Aristotle [XI: 1452a32-33], 'a change from ignorance to knowledge' in the protagonist of a tragedy, e.g. Oedipus' realisation that he has both killed his father and married his mother in Oedipus Rex. The recognition I have in mind is when the audience comes to realise that they have experienced a particular experience of a particular character for themselves in virtue of the narrative framework. This recognition may occur during or after the experience of the representation and occurs when, e.g., I realise that both Romeo and I have forgotten about Rosaline or that both Leonard and I cannot make sense of what is happening to him. In a similar manner to that in which anagnorisis provides the protagonist with knowledge, so the recognition with which I am concerned provides the audience with LPK. The provision of LPK thus requires not only the reproduction of the experiential structure, but the recognition of this reproduction by the audience. The reproduction itself is, as I mentioned in section 2, a rarity and the acquisition of LPK will be limited to those members of the audience who both adopt the SME and recognise the reproduction. 
LPK provided in this manner is related to identification because the acquisition of LPK may encourage identification with, e.g., Romeo or Leonard, but identification is an effect of LPK rather than - as in Ribeiro's explanation - its cause. Although Ribeiro mentions recognition as well, her variant is a gradual realisation of the cumulative process of identification that occurs during the course of the poetic experience. Following Aristotle, the recognition by means of which LPK is provided is sudden and instantaneous. Furthermore, and crucially, it is a recognition that a particular experience which can readily be specified and admits of paraphrase has been reproduced. I shall call this recognition, which is characteristically both sudden and specifiable, audience-anagnorisis in order to distinguish it from both Aristotle's anagnorisis and Ribeiro's recognition. In the SME, the audience accepts the author's invitation to adopt a particular narrative framework; in cases where a narrative representation provides LPK, the adoption of that framework will involve the realisation that a particular experience of a particular character has been reproduced in the audience. This realisationand thus the specific LPK - is acquired in a moment of audience-anagnorisis in which the audience recognises the reproduction of the experiential structure in question. Audienceanagnorisis is the process by which LPK is provided by exemplary narratives and is clearly distinct from the experience of identification that Ribeiro describes. Even if there is no significant distinction between poetic and narrative frameworks, therefore, LPK cannot be reduced to identification.

\section{Narrativity Criterion: Aesthetic Properties}

If there is a significant distinction between poetic and narrative frameworks, then it is curious that two different types of frameworks invite a similar SME (as noted in section 4). This suggests that the narrative framework with which I am concerned might not be a function of 
the narrative properties of a representation, but of other properties and - given that poems and exemplary narratives are often works of art - the obvious choice is aesthetic properties. ${ }^{10}$

The objection is thus that when LPK is provided by narrative representations, it is provided in virtue of their aesthetic rather than narrative properties. I do not wish to either commit to a definition of aesthetic properties or to argue for a theory of art so I shall adopt the following strategy: if there is a narrative representation that is not a work of art but which provides LPK, then the objection that NC does not meet the narrativity criterion (because LPK is provided by aesthetic properties) fails. There is difficulty in selecting such an example because many exemplary narratives that are not canonical works of art - e.g., a work of propaganda like Triumph of the Will - are often cited as having aesthetic properties. I shall nonetheless employ Morgan Spurlock's Super Size Me, on the basis that the work's artistic status has not played a significant role in either its production or reception. The documentary was intended to demonstrate the physical and mental dangers of eating too much fast food and the immorality of companies like McDonald's in not only selling their products, but maximising their revenue by encouraging people to eat more - super size - on each occasion. The film was nominated for the Academy Award for Best Documentary in 2004 and responses have been primarily concerned with the validity of the experiment represented in the narrative, the profundity - or lack thereof - of the narrative's message, and the effect of the narrative on the McDonald's Corporation.

Spurlock's film records the experiment he conducted on himself by eating all of his meals from McDonald's for a period of thirty days. The health dangers were heightened by several factors, e.g. he decided to super size his order whenever McDonald's staff made the offer and to finish all of each meal regardless of his appetite. The narrative is filmed largely from

\footnotetext{
${ }^{10}$ Recall that for the purposes of this paper I am assuming a close relationship between aesthetic value and the value of art qua art and thus between aesthetic and artistic properties. If this relationship is disputed, one could simply replace 'aesthetic' with 'artistic' in this section.
} 
Spurlock's point of view, is narrated by him, and involves him both conducting interviews and addressing the audience directly. The documentary represents Spurlock's experience of his own experiment and the SME invites one to adopt his framework on the phenomenon of fast food, which changes from curiosity to antipathy as the narrative progresses. In this respect it can be said to provide both knowledge that (in the numerous statistics narrated and depicted) and PK (knowledge of what it is like to live on fast food). In addition to the PK provided, the narrative framework provides LPK by reproducing Spurlock's experience of being disgusted by fast food. This is achieved by stylistic choices that make both indirect and direct links between repulsive images and McDonald's products by means of the narrative perspective. There are, e.g., several close-ups of a gastric bypass operation on a man whose obesity has become life-threatening. On the second day of Spurlock's experiment (approximately 20 minutes into the 98 minute documentary) there are close-ups of his physical distress as he struggles to finish a super size meal and his subsequent vomiting of that meal onto the pavement. Disgust is also stimulated in more subtle ways: Spurlock joins a children's party for his final meal and images of him eating a sickly-sweet birthday cake are juxtaposed with chips being deep-fried in a sea of fat. The knowledge provided is not merely PK, but LPK because Spurlock's experience of being disgusted by fast food is reproduced in the audience, who recognise the shared disgust in a moment of audience-anagnorisis. As an exemplary narrative that is both (1) lacking in aesthetic properties and (2) provides LPK, Super Size Me thus offers evidence that LPK does meet the narrativity criterion for NC.

My argument for $\mathrm{NC}$ is therefore that: a subset of narrative representations (exemplary narratives) can provide a particular type of knowledge (LPK) in virtue of their narrativity. I have demonstrated that LPK meets both the epistemic and narrative criteria for NC, i.e. evidence for the acquisition of LPK can be produced and LPK is provided by the narrative 
framework through the process of audience-anagnorisis. Finally, I have shown that LPK is acquired in virtue of the narrative rather than aesthetic properties of a representation. Many philosophers will not be convinced by this last claim. First, Super Size Me is not as paradigmatic an example of LPK as Romeo and Juliet and Memento. If the criterion for LPK in Super Size Me is that viewers are at least temporarily disgusted by fast food, there may well be critical debate about the role played by disgust in the SME. Second, if Super Size Me does provide LPK, as I maintain, then the techniques I described in creating the audienceanagnorisis seem to be precisely aesthetic techniques, in which case the properties I have discussed throughout this paper are a sub-category of aesthetic properties, a possibility I mentioned in section 1. If narrative properties are a sub-category of aesthetic properties then my argument for $\mathrm{NC}$ is also an argument for AC: a subset of works of art (those that are also exemplary narratives) can provide knowledge (LPK) in a manner that is aesthetically relevant (in virtue of their narrativity).

I think there is at least one reason to be cautious about this argument for $\mathrm{AC}$, which is that the distinction between narrative and non-narrative representations is more fundamental than the distinction between artistic and non-artistic representations when one is considering the cognitive value of representations. The difference in significance between two distinct but overlapping oppositions can be problematic, as Derek Matravers has shown in Fiction and Narrative. Matravers [2014: 47] contends that the distinction between confrontations (where action is possible) and representations (where action is not possible) is more fundamental than the distinction between non-fiction and fiction. The failure to recognise the significance of the former distinction has resulted in philosophers restricting certain claims to fictions when they are in fact true of all representations [Matravers 2014: 87]. Employing Ryle's [1971] thick-thin distinction, Matravers [2014: 46-47] argues that the engagements with both 
Tolstoy's War and Peace and Faber de Faur's With Napoleon in Russia result in a thick experience. What is important about the novel and the memoir is that they are both thick representations - i.e. vivid, rich, and gripping - an insight which is lost when the property of thickness is restricted to fictional representations.

In a mirror-image of Matravers' concern, mine is that the failure to recognise the significance of the distinction between narrative and non-narrative representations will encourage the conflation of narrative properties and aesthetic properties such that claims which should be restricted to narrative works of art are extended to (potentially) all works of art. If this seems unlikely, recall the subtlety of the distinction between the identification produced by poetic frameworks and the provision of LPK by means of narrative frameworks discussed in section 5. I am not convinced that non-narrative representations, whether linguistic or visual, can provide LPK. If narrative properties are a sub-category of aesthetic properties - as seems likely - then different sub-categories of aesthetic properties appear to have distinct relations to cognitive value. A detailed discussion of aesthetic properties is beyond the scope of this paper and my preference is therefore to err on the side of caution and restrict my argument to $\mathrm{NC}$, the provision of LPK by exemplary narratives in virtue of their narrativity. My claim is, in other words, that stories can provide genuine knowledge just by being stories and irrespective of their truth value. ${ }^{11}$

University of York

\footnotetext{
${ }^{11}$ I would like to thank John Gibson, Peter Lamarque, Derek Matravers, Tzachi Zamir, and three anonymous referees from this journal for their invaluable assistance with this paper.
} 


\section{References}

Aristotle 2004. Poetics, trans. P. Murray and T.S. Dorsch, in Classical Literary Criticism, ed. P. Murray, London: Penguin: 57-97.

Burri, Alex 2007. Art and the view from nowhere, in A Sense of the World: Essays on fiction, narrative, and knowledge, eds John Gibson, Wolfgang Huemer, and Lucca Pocci, London: Routledge: 308-17.

Carroll, Noël 2001. Beyond Aesthetics: Philosophical Essays, New York: Cambridge University Press.

Carroll, Noël 2010 (2012). Art in Three Dimensions, Oxford: Oxford University Press. Carroll, Noël 2013. Minerva's Night Out: Philosophy, Pop Culture, and Moving Pictures, Malden, MA: Wiley-Blackwell.

Currie, Gregory 2010. Narratives \& Narrators: A Philosophy of Stories, Oxford: Oxford University Press.

Fabb, Nigel 2009. Why is Verse Poetry? PN Review 189: 36/1: 52-57.

Gibson, John 2008. Cognitivism and the Arts, Philosophy Compass 3/4: 573-589.

Gibson, John 2011. The Question of Poetic Meaning, Nonsite 4, URL =

$<$ http://nonsite.org/article/the-question-of-poetic-meaning $>$.

Goldie, Peter 2012. The Mess Inside: Narrative, Emotion, and the Mind, Oxford: Oxford University Press.

Lamarque, Peter 2009. Poetry and Abstract Thought, Midwest Studies in Philosophy XXXIII: 37-52.

Lamarque, Peter 2014. The Opacity of Narrative, London: Rowman \& Littlefield International.

Matravers, Derek 2014. Fiction and Narrative, Oxford: Oxford University Press.

McGregor, Rafe 2014. Cinematic Philosophy: Experiential Affirmation in Memento, The Journal of Aesthetics and Art Criticism 72/1: 57-66.

Ribeiro, Anna Christina 2009. Toward a Philosophy of Poetry, Midwest Studies in Philosophy XXXIII: 61-77.

Ryle, Gilbert 1971. The Thinking of Thoughts: What is 'Le Penseur' Doing? in Volume II: Collected Essays 1929-1969, G. Ryle, London: Hutchinson \& Co.: 480-96.

Thomson-Jones, Katherine 2005. Inseparable Insight: Reconciling Cognitivism and Formalism in Aesthetics, The Journal of Aesthetics and Art Criticism 63/4: 375-84.

Walsh, Dorothy 1969. Literature and Knowledge, Middletown, CT: Wesleyan University Press.

White, Hayden 1980. The Value of Narrativity in the Representation of Reality, Critical Inquiry 7/1: 5-27.

Wilson, Catherine 1983. Literature and Knowledge, Philosophy 58/226: 489-496.

Zamir, Tzachi 2007. Double Vision: Moral Philosophy and Shakespearean Drama, Princeton: Princeton University Press. 